\title{
PECTORALIS MAJOR TRANSFER FOR PARALYSIS OF ELBOW FLEXION IN CHILDREN
}

\author{
R. M. ATKINS, M. J. BELL, W. J. W. SHARRARD \\ From the Children's Hospital, Sheffield
}

\begin{abstract}
Seven pectoralis major transfers in children suffering from bilateral paralysis of elbow flexion due to arthrogryposis or to trauma are reported. A technique is described in which the muscle is mobilised from the clavicle to allow the tendon of insertion to be attached to the biceps tendon at the elbow. The biceps tendon was found to be present and could be mobilised forwards in all the arthrogrypotic elbows.

Subjectively, the results were considered by patients or parents to be very good in six cases and fair in one. Elbow flexion power against gravity and against some resistance was achieved in all patients except one. The overall function was very good in one elbow, good in two, fair in three and poor in only one. The merits of the various procedures described for the restoration of elbow flexion in arthrogryposis are discussed. It is concluded that total pectoralis major transfer by the method described here has given the best results.
\end{abstract}

Complete loss of power of elbow flexion is a severe disability. The possible causes in childhood include trauma, either direct or to the brachial plexus, poliomyelitis and arthrogryposis. In arthrogryposis, the disability is particularly severe because it is frequently bilateral.

Seven types of operation have been used to try to overcome the deficit.

1. Proximal transfer of the common flexor (Steindler 1939) or the common flexor and extensor origins.

2. Transfer of triceps to biceps brachii (Bunnell 1951; Carroll 1952; Caroll and Hill 1970).

3. Transposition of sternomastoid to biceps brachii (Bunnell 1951: Carroll 1962).

4. Transposition of latissimus dorsi to biceps brachii (Schottstaedt, Larsen and Bost 1955; Hovnanian 1956: Axer. Segal and Elkon 1973; Zancolli and Mitre 1973).

5. Transfer of pectoralis minor to biceps brachii (Le Coeur 1953: Spira 1957; Masse and Morchoisne 1967).

6. Transfer of pectoralis major to biceps brachii or to a forearm bone (Clark 1946; Brooks and Seddon 1959: Dautry et al. 1978; Carroll and Kleinman 1979): and

7. Transfer of pectoralis major and pectoralis minor (Tsai et al. 1983).

R. M. Atkins, MA, FRCS, Rescarch Registrar. Department of Human Metabolism

M. J. Bell. FRCS. Senior Orthopaedic Registrar

Royal Hallamshire Hospital. Glossop Road. Sheffield S10 2JF, England.

W. J. W. Sharrard. MD. ChM. FRCS. Consultant Orthopaedic Surgeon 140 Manchester Road. Sheffield S10 5DL. England.

Requests for reprints should be sent to Mr W. J. W. Sharrard.

( 1985 British Editorial Society of Bone and Joint Surgery $0301620 \times 854127 \$ 2.00$
Table I. Details of cases

\begin{tabular}{|c|c|c|c|c|c|}
\hline Case & Diagnosis & Sex & $\begin{array}{l}\text { Age at } \\
\text { operation } \\
\text { (years) }\end{array}$ & Type of transfer & $\begin{array}{l}\text { Follow-up } \\
\text { (months) }\end{array}$ \\
\hline 1 & $\begin{array}{l}\text { Brachial } \\
\text { plexus } \\
\text { lesion }\end{array}$ & $\mathrm{F}$ & 8 & $\begin{array}{l}\text { Total pectoralis } \\
\text { major transfer }\end{array}$ & 96 \\
\hline$* 2(R)$ & Arthrogryposis & M & 3 & $\begin{array}{l}\text { Total pectoralis } \\
\text { major transfer }\end{array}$ & 48 \\
\hline$* 3(\mathrm{~L})$ & & & 5 & $\begin{array}{l}\text { Total pectoralis } \\
\text { major transfer }\end{array}$ & 24 \\
\hline 4 & Arthrogryposis & $\mathrm{F}$ & 6 & $\begin{array}{l}\text { Total pectoralis } \\
\text { major transfer }\end{array}$ & 121 \\
\hline 5 & Arthrogryposis & $\mathrm{F}$ & 6 & Clark transfer & 180 \\
\hline 6 & Arthrogryposis & $\mathbf{M}$ & 2 & $\begin{array}{l}\text { Total pectoralis } \\
\text { major transfer }\end{array}$ & 15 \\
\hline 7 & Arthrogryposis & $\mathrm{F}$ & 3 & $\begin{array}{l}\text { Total pectoralis } \\
\text { major transfer }\end{array}$ & 12 \\
\hline 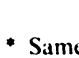 & atient. & & - & & \\
\hline
\end{tabular}

Since Clark's first description in 1946 of a pectoralis major transfer, a number of variations of this transfer have been described. This paper describes a new technique for total transfer of the muscle and reports the results in seven children.

\section{PATIENTS AND METHODS}

Six patients underwent seven total pectoralis major transfers (Table I) while one was treated by Clark's (1946) type of transfer. All suffered from bilateral impairment of elbow flexion, and in five patients there was complete bilateral paralysis of elbow flexion due to arthrogryposis. The sixth patient, having had a traffic accident, was left with a spastic and almost functionless 


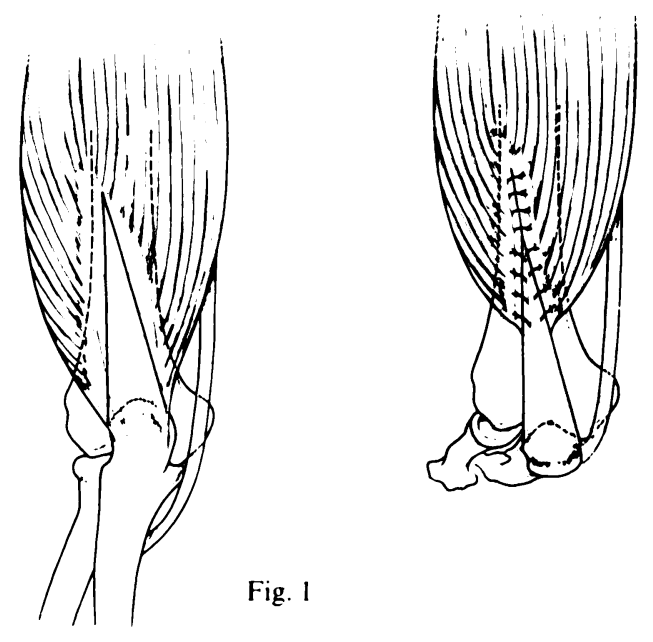

The technique of tricepsplasty is shown in Figure 1. Figures 2 and 3 illustrate the technique of total pectoralis major transfer: Figure 2 shows the exposed pectoralis major and Figure 3 illustrates the subcutaneous tunnel (note the flexed position).

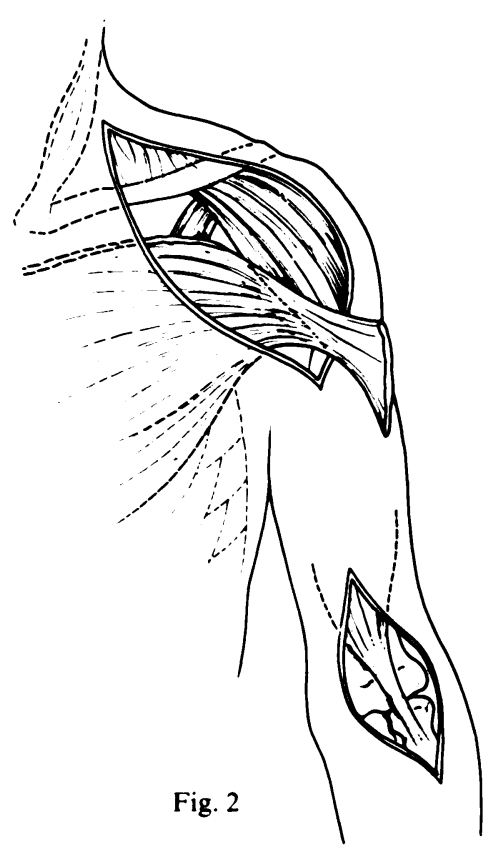

left upper limb as well as a brachial plexus injury of the right upper limb with complete paralysis of elbow flexion.

The pectoralis major muscle was strong (MRC Grade 4 or better) in all limbs treated by pectoralis major transfer. Forearm and hand function was adequate. The overwhelming disability was loss of any ability to flex the elbow actively. All the arthrogrypotic patients had a limited range of elbow flexion due to shortness of the triceps and, in four limbs triceps elongation was needed before, or in association with, pectoralis major transfer.

Operative technique. Tricepsplasty (Fig. 1). In two patients (Cases 6 and 7) there was severe triceps contracture with complete fixed extension of the elbow. An extensive VY-plasty of the triceps and posterior capsulotomy of the elbow was performed as a separate operation and gave a range of flexion of 110 . In another patient the limitation of flexion was in both elbows but was less severe; tricepsplasty was performed at the same time as pectoralis major transfer (Cases 2 and 3).

Total pectoralis major transfer (Figs 2 and 3). A curved incision was made from four centimetres below the medial third of the clavicle along the line of the deltopectoral groove to the junction of the middle and upper third of the upper arm. The upper half of the pectoralis major muscle was exposed. The clavicular head, supplied by the fifth and sixth cervical nerve roots, was atrophic in all cases except one; it was detached completely from the clavicle and the uppermost part of the sternum. The tendon of insertion of the muscle was detached from the humerus as close to the bone as possible and was lengthened by including any available fascia distally. Detachment of the clavicular fibres allowed the muscle to be displaced distally to reach to within two or three centimetres of the elbow. The neurovascular bundles supply- ing the muscle on its deep surface were mobilised carefully to avoid damage or excessive tension.

A second incision, L-shaped, was made at the elbow; its transverse limb was in the flexor crease of the elbow and its longitudinal limb extended proximally along the medial border of the biceps tendon, sometimes joining the first incision. In arthrogrypotics, the biceps tendon and muscle were atrophic and the muscle was usually replaced by fat. Nevertheless, although the tendon was closely adherent to the anterior capsule of the elbow, it could always be identified. Traction on the atrophic tendon at this point failed to flex the elbow. The tendon was dissected to its insertion into the bicipital tubercle and allowed to bowstring forwards. After this dissection, traction on the tendon did lead to flexion of the elbow.

A tunnel was made subcutaneously between the two incisions. Through this, the tendon of the pectoralis major was passed to the distal incision and was attached to the biceps tendon with non-absorbable sutures, keeping the elbow flexed as fully as possible.

After closing the incisions with vacuum drains, the limb was immobilised with the elbow fully flexed and the upper arm by the side in a collar-and-cuff sling and elastic strapping. Immobilisation was maintained for three weeks followed by muscle re-education. The elbow was allowed to extend gradually over the course of the next six weeks. Recovery in all cases was uneventful with no complications.

One patient who was treated by a Clark type of transfer initially had a poor result with active elbow flexion power of MRC Grade 3 but with only a $30^{\circ}$ range of active flexion from the extended position. Three years after the initial operation, the transplanted muscle was shortened by reefing, with an improved result. 


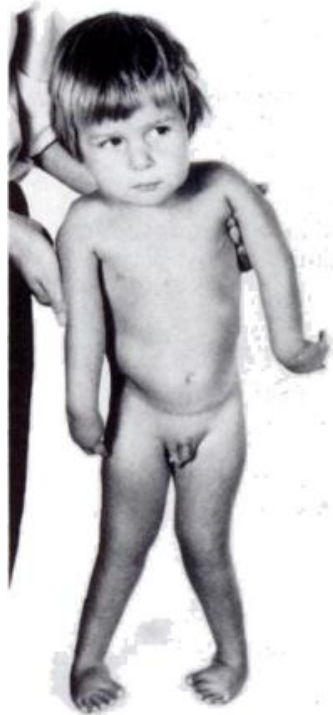

Fig. 4

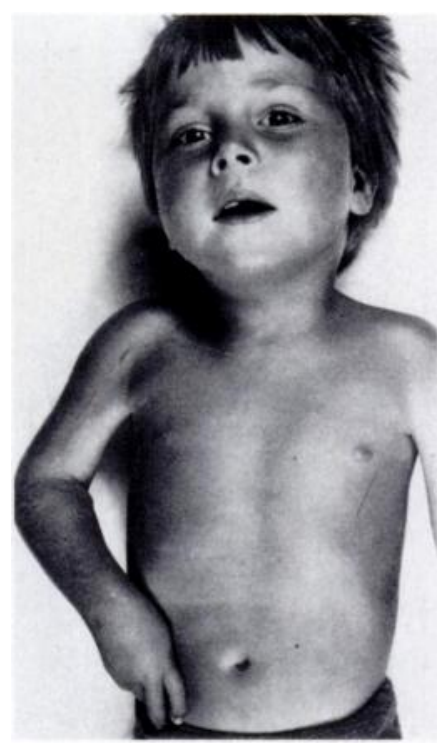

Fig. 5

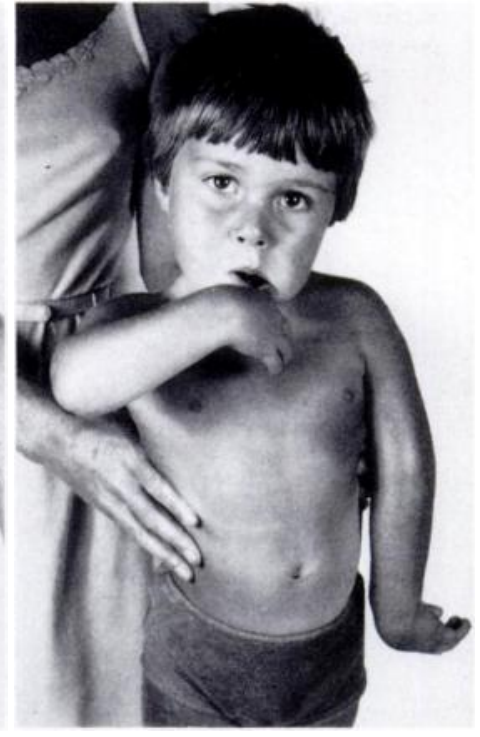

Fig. 6

Figure 4-An arthrogrypotic child, aged two, before operation. There was no passive or active elbow flexion but the triceps was active. An extensive tricepsplasty was needed before pectoralis major transfer. Figure 5-One year after total pectoralis major transfer: the contracting transferred muscle can be seen in the upper arm and there is no webbing of the axillary fold. Note the line of the L-shaped incision. Figure 6-The range of elbow flexion allows the child to feed himself.

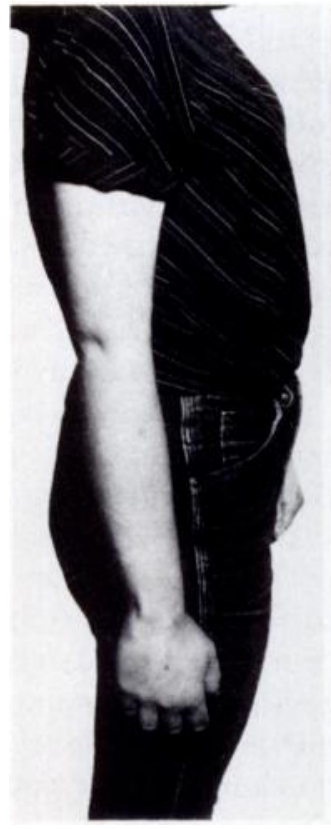

Fig. 7

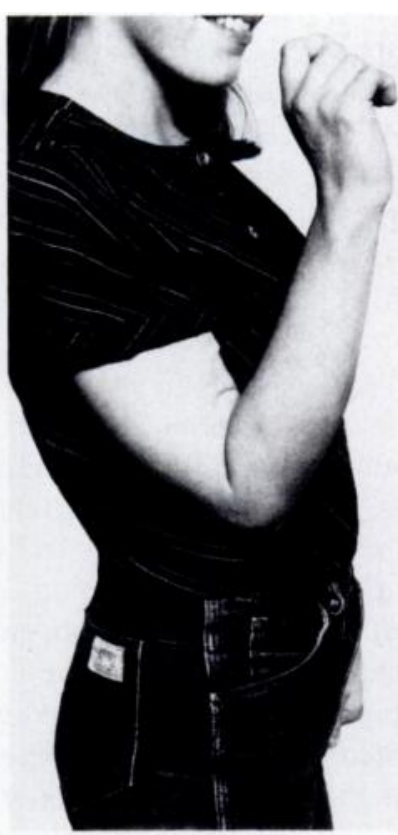

Fig. 8

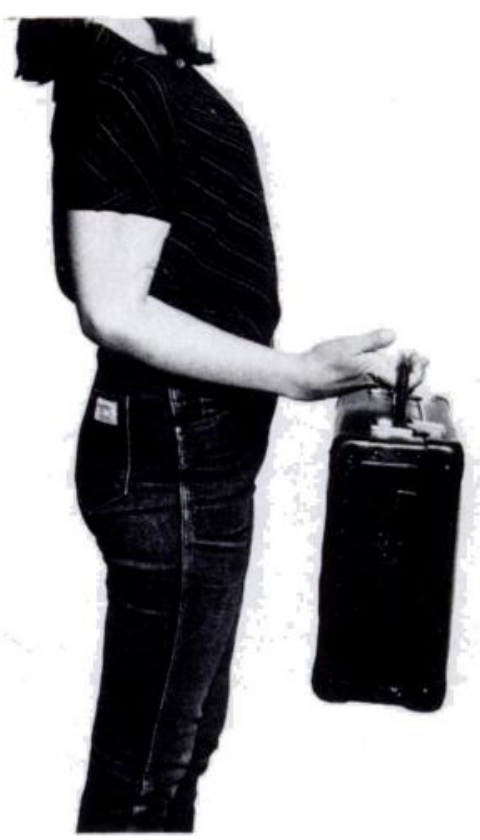

Fig. 9

Figures 7 to 9--A girl aged 16, eight years after total pectoralis major transfer. There is active flexion against gravity and resistance. 
Table II. Results of pectoralis major transfer

\begin{tabular}{|c|c|c|c|c|c|c|c|}
\hline \multirow[b]{3}{*}{ Case } & \multicolumn{2}{|c|}{ Before operative treatment } & \multicolumn{3}{|c|}{ At follow-up } & \multicolumn{2}{|l|}{ Assessment of function } \\
\hline & \multirow{2}{*}{$\begin{array}{l}\text { Range of } \\
\text { movement }\end{array}$} & \multirow{2}{*}{$\begin{array}{l}\text { Elbow flexor } \\
\text { power (MRC grade) }\end{array}$} & \multicolumn{2}{|c|}{ Range of movement } & \multirow{2}{*}{$\begin{array}{l}\text { Elbow flexor } \\
\text { power }\end{array}$} & \multirow[b]{2}{*}{ Subjective } & \multirow[b]{2}{*}{ Objective } \\
\hline & & & Passive & Active & & & \\
\hline 1 & Full & 0 & Full & $0-120$ & 4 & $\begin{array}{l}\text { Very good: independent, attends normal } \\
\text { school, can feed, attend to toilet, dress, } \\
\text { bathe, lift bag; cannot wash hair }\end{array}$ & Very good \\
\hline $2(R)$ & 090 & 0 & $5-90$ & $5-80$ & $3+$ & $\begin{array}{l}\text { Very good }(R) \text { and fair }(L) \text { : plays nor- } \\
\text { mally and independently, attends normal } \\
\text { school, can feed, attend to toilet, dress. }\end{array}$ & Fair (R) \\
\hline $3(\mathrm{~L})$ & 090 & 0 & $30-100$ & $30-50^{\circ}$ & 3 & bathe & Poor (L) \\
\hline 4 & 20160 & 2 & $50-130$ & $50-100$ & 4 & $\begin{array}{l}\text { Very good: independent, attends college, } \\
\text { can carry bag, feed, attend to toilet, dress, } \\
\text { bathe independently with aids; cannot } \\
\text { wash hair }\end{array}$ & Good \\
\hline 5 & $0-90$ & 0 & $20-110$ & $20-75 *$ & $3+*$ & $\begin{array}{l}\text { Very good: in wheelchair, drives a car, can } \\
\text { feed, attend to toilet, dress; cannot wash } \\
\text { hair }\end{array}$ & Fair \\
\hline 6 & 0 & 0 & $40-110$ & $40-110^{\circ}$ & 4 & Very good: can feed and dress himself & Good \\
\hline 7 & 0 & 0 & $45-110$ & 45100 & $3+$ & Very good: can feed and dress herself & Fair \\
\hline
\end{tabular}

* This patient had a Clark type procedure and after 3 years had active flexion of MRC Grade 3 with a range of active flexion of 30 from full extension. The transplanted muscle was therefore reefed, giving the results quoted.

Method of analysis. A subjective assessment of the result was made by the patient or his parents, with particular reference to success in using the limb and of independence in ability to feed, attend to toilet needs, dress, wash and comb the hair, bathe and carry objects. The result was rated as very good or good when the operation was felt to have been a success; fair when it was successful up to a point; and poor when it was felt that there had been no real change in function.

Objective assessment was based on the power of elbow flexion using the Medical Research Council grading of muscle power and the range of active and passive elbow movement.

\section{RESULTS}

The results are shown in Table II. The mean follow-up time was six years with a minimum of 12 months and a maximum of 15 years.

Subjectively, all the patients or their parents were pleased with the results and rated them as very good or good in all but one elbow. In every patient, improved function contributed considerably to their independence (Figs 4 to 6). This was particularly significant since all the patients suffered from bilateral paralysis.

The objective assessments showed that, in all but one case, there was loss of range of elbow extension but this did not cause difficulty or disability. The power of elbow flexion was Grade $3+$ or better (Figs 7 to 9) in all but one elbow. All patients said that, in order to initiate flexion of the elbow in the early days of muscle re-education, they had had to adduct and medially rotate the shoulder but, in time, this did not cause discomfort and they adjusted to it. Some adduction, medial rotation and elevation of the shoulder during active elbow flexion was observed objectively in some patients, but it did not interfere with function. The overall objective assessment of the result was considered to be very good in one elbow, good in two, fair in three and poor in one. Failure to flex to $90^{\circ}$ combined with poor muscle power was responsible for the poor result.

An advantage of the total pectoralis major transfer was a scar (Fig. 5) which was more acceptable than after the Clark type of operation, in which, moreover, the incision had to pass close to the breast disc, possibly leading to its poor development. The extent of dissection and blood loss was considerably less in this operation than in the Clark procedure. Webbing of the axillary fold, which has been a criticism of pectoralis major transfer, was not a problem in these cases (Fig. 5).

\section{DISCUSSION}

Brooks and Seddon (1959) suggested that, unlike the Clark procedure, their method of pectoralis major transfer allowed the whole of the muscle to be used rather than the sternal portion alone. This is an important consideration in treating arthrogryposis. The technical difference between the Brooks-Seddon operation and our own is that, in theirs, the tendon of pectoralis major is attached to the proximal tendon of origin of the long head of the biceps brachii and the central part of the paralysed muscle is converted to a fibrotendinous structure by devascularisation. In our operation the detachment of the pectoralis major origin from the clavicle allows it to be mobilised distally so that it can always be 
sutured to the tendon of insertion of the biceps. LloydRoberts and Lettin (1970) and Williams (1973) both state that the biceps tendon of insertion is absent in arthrogryposis. Our findings contradict this. The biceps tendon was always present but needed to be mobilised from the elbow capsule.

All the modifications of the Clark transfer used by Lloyd-Roberts and Lettin (1970), Carroll and Kleinman (1979) and Doyle et al. (1980) have the disadvantage of a long scar and an extensive dissection. The total pectoralis major transfer described in this paper requires less dissection. gives a smaller scar and has given better results with regard to muscle power and the ability to feed, attend to toilet, dress and bathe independently.

Brooks and Seddon (1959) advocated arthrodesis of the shoulder to minimise its medial rotation during action of the transferred muscle, and Dautry et al. (1978) transferred the tendons of teres major and latissimus dorsi posteriorly to counteract this medial rotation. Although medial rotation of the shoulder did occur in our cases, it was not excessive and did not interfere with function. It may be that total transfer of the muscle, leaving no part able to act as a direct medial rotator, avoided this problem.

Limited elbow movement is a feature of arthrogryposis and, in our patients, was often severe before surgical treatment. Some limitation of elbow flexion, even after extensive tricepsplasty, had to be accepted in patients who initially had no range of passive flexion at all: however, we found that an active range of flexion of 90 or more was quite acceptable and was consistent with a good subjective and objective result.

We believe that our results compare favourably with other methods described for arthrogryposis. Williams (1973) obtained elbow flexion by anterior transfer of the triceps brachii. Although he records good results, he makes no comment about loss of elbow extensor power, which is important if the patient needs to use sticks, elbow crutches or a wheelchair. In all our patients, active extension of the elbow was retained. In treating arthrogryposis Doyle et al. (1980) prefer pectoralis major transfer to triceps transfer or proximal transfer of the common flexor origin. The results in this series of pectoralis major transfers in children, most of whom were arthrogrypotics, confirm this view.

\section{REFERENCES}

Axer A, Segal D, Elkon A. Partial transposition of the latissimus dorsi: a new operative technique to restore elbow and finger flexion. $J$ Bone Joint Surg $[\mathrm{Am}]$ 1973:55 A: 1259-64.

Brooks DM, Seddon HJ. Pectoral transplantation for paralysis of the flexors of the elbow: a new technique. J Bone Joint Surg [Br] 1959: 41 B: 3643 .

Bunnell S. Restoring flexion to the paralytic elbow. J Bone Joint Surg $[\mathrm{Am}] 1951: 33-\mathbf{A}: 566-71$.

Carroll RE. Restoration of flexor power to flail elbow by transplantation of triceps tendon. Surg Ginecol Ohstet 1952:95:685 8.

Carroll RE. Restoration of elbow flexion by transplantation of the sternocleidomastoid muscle. J Bone Joint Surg $[\mathrm{Am}]$ 1962: $44 \mathrm{~A}$ : 1039.

Carroll RE, Hill NA. Triceps transfer to restore elbow flexion: a study of fifteen patients with paralytic lesions and arthrogryposis. $J$ Bone Joint Surg $[A m] 1970: 52$ A:239 44.

Carroll RE, Kleinman WB. Pectoralis major transplantation to restore elbow flexion to the paralytic limb. J Hand Surg 1979:4:501-7.

Clark JMP. Reconstruction of biceps brachii by pectoral muscle transplantation. Br J Surg 1946:34:180 1.

Dautry P, Apoil A, Moinet F, Koechlin P. Paralysie radiculaire supérieure du plexus brachial. Traitement par transpositions musculaires associées: résultat de sept cas. Rev Chir Orthop 1978:64: 399407.

Doyle JR, James PM, Larsen LJ, Ashley RK. Restoration of elbow flexion in arthrogryposis multiplex congenita. J Hand Surg 1980: 5: 14952 .

Hovnanian AP. Latissimus dorsi transplantation for loss of flexion or extension at the elbow: a preliminary report on technic. Ann Surg 1956:143:493-9.

Le Coeur M. Procédés de restauration de la flexion du coude paralytique. Rev Chir Orthop 1953:39:655 6.

Lloyd-Roberts GC, Lettin AWF. Arthrogryposis multiplex congenita. J Bone Joint Surg 1970:52 B:494 508.

Masse P, Morchoisne P. Restauration de la flexion du coude paralytique par transplantation du petit pectoral: operation de Pol Le Coeur. Rev Chir (Orthop) 1967:53:357 72.

Schottstaedt ER, Larsen LJ, Bost FC. Complete muscle transposition. $J$ Bone Joint Surg $[\mathrm{Am}]$ 1955:37 A:897 919.

Spira E. Replacement of biceps brachii by pectoralis minor transplant: report of a case. J Bone Joint Surg [Br] 1957:39-B:126 7.

Steindler A. Tendon transplantation in the upper extremity. Amer $J$ Surg 1939:44:260 71 .

Tsai T-M, Kalisman M, Burns J, Kleinert HE. Restoration of elbow flexion by pectoralis major and pectoralis minor transfer. $J$ Hand Surg 1983:8: 186 -90.

Williams PF. The elbow in arthrogryposis. J Bone Joint Surg [Br] 1973; 55-B: $834-40$

Zancolli E, Mitre H. Latissimus dorsi transfer to restore elbow flexion: an appraisal of eight cases. J Bone Joint Surg $[\mathrm{Am}]$ 1973:55 A: 126575 . 